\title{
ION BEAM MATERIALS ANALYSIS AND MODIFICATIONS AT keV TO MeV ENERGIES AT THE UNIVERSITY OF NORTH TEXAS
}

\author{
BIBHUDUTTA ROUT, MANGAL S. DHOUBHADEL, PRAKASH R. POUDEL ${ }^{+}$, \\ VENKATA C. KUMMARI*, WICKRAMAARACHCHIGE J. LAKSHANTHA, JACK E. MANUEL, \\ GYANENDRA BOHARA, SZABOLCS Z. SZILASI, GARY A. GLASS, FLOYD D. MCDANIEL \\ Ion Beam Modification and Analysis Laboratory, Department of Physics, University of North Texas, \\ 1155 Union Circle \#311427, Denton, Texas 76203 USA \\ mcdaniel@unt.edu
}

Published 25 February 2014

\begin{abstract}
The University of North Texas (UNT) Ion Beam Modification and Analysis Laboratory (IBMAL) has four particle accelerators including a National Electrostatics Corporation (NEC) 9SDH-2 3 MV tandem Pelletron, a NEC 9SH 3 MV single-ended Pelletron, and a $200 \mathrm{kV}$ CockcroftWalton. A fourth HVEC AK 2.5 MV Van de Graaff accelerator is presently being refurbished as an educational training facility. These accelerators can produce and accelerate almost any ion in the periodic table at energies from a few $\mathrm{keV}$ to tens of $\mathrm{MeV}$. They are used to modify materials by ion implantation and to analyze materials by numerous atomic and nuclear physics techniques. The NEC 9SH accelerator was recently installed in the IBMAL and subsequently upgraded with the addition of a capacitive-liner and terminal potential stabilization system to reduce ion energy spread and therefore improve spatial resolution of the probing ion beam to hundreds of nanometers. Research involves materials modification and synthesis by ion implantation for photonic, electronic, and magnetic applications, micro-fabrication by high energy (MeV) ion beam lithography, microanalysis of biomedical and semiconductor materials, development of highenergy ion nanoprobe focusing systems, and educational and outreach activities. An overview of the IBMAL facilities and some of the current research projects are discussed.
\end{abstract}

Keywords: Particle accelerator; ion implantation; ion beam analysis; ion microprobe.

\section{Introduction}

At this time, there are more than 30,000 particle accelerators in operation around the world that are used for research and applications in medicine, industry, energy, the environment, national security, and discovery science. The increased utility and applications of particle accelerators have been presented at a number of conference venues and are well described at a U.S. Department of energy website, www.acceleratorsamerica.org.

\footnotetext{
${ }^{+}$Present address at Intel Corporation, 1600 Rio Rancho Boulevard Southeast, Rio Rancho, NM 87124, USA.
}

* Present address at Intel Corporation, 2501 NW 229th Avenue, Hillsboro, OR 97124, USA.

This is an Open Access article published by World Scientific Publishing Company. It is distributed under the terms of the Creative Commons Attribution 3.0 (CC-BY) License. Further distribution of this work is permitted, provided the original work is properly cited. 
The Accelerators for America's Future website grew out of a 2009 symposium, sponsored by the U. S. Department of Energy. At this symposium, working groups discussed the needs, challenges, areas of greatest promise, and bridging the gap between accelerator research and technological deployment for the above topics.

A portion of the UNT Ion Beam Modification and Analysis Laboratory (IBMAL) accelerator research activities are involved with the synthesis and characterization of electronic, magnetic, biomedical, and luminescent materials. While some research projects require the use of broad ion beams $(>1 \mathrm{~mm})$, some require the use of high energy focused ion beams for micro-fabrication and micro-analysis. In this paper we have presented a summary of the IBMAL accelerator facilities and current research projects.

\subsection{Light emitting materials}

Silicon-based electronic materials are used for many applications in integrated circuits, computer memories, current amplification, etc. However, because Si has an indirect band gap, light emission applications are limited. As early as 1990, Canham demonstrated that porous silicon structures emit visible light. ${ }^{1}$ Since that time, a number of researchers have synthesized a number of light-emitting Si nanostructures in thin film Si-oxide based materials. $^{2,3}$ In addition, other research groups have reported luminescence from Ge nanocrystals, ${ }^{4} \mathrm{C}$ nanoclusters, ${ }^{5}$ and $\mathrm{SiC}$ nanocrystals ${ }^{6}$ that were synthesized in $\mathrm{SiO}_{2}$. While intense luminescence is not observed in bulk silicon, nanostructures synthesized in Si-based materials can produce the desired luminescence due to the quantum size effects of the Si nanoparticles and could possibly be used for applications in solid-state lighting and photovoltaic solar panels. ${ }^{7}$ The presence of transition metallic nanoparticles (e.g., Ag and $\mathrm{Au}$ ) near the vicinity of $\mathrm{Si}$ nanostructures has contributed to the enhanced emission ${ }^{8}$ and absorption of the lights in many systems including solar cells. ${ }^{7}$ At IBMAL, current research involves synthesis of optically active nanostructures in Si based matrices via ion implantation and the investigation of the origin and efficiency of emission and absorption of light at various wavelength ranges due to these nanostructures. ${ }^{8-12}$

\subsection{Materials analysis and fabrication using ion microprobes}

In the last few decades, the development of high energy $(\mathrm{MeV})$ focused ion beam systems (HEFIB) has fostered new research in many disciplines including metallurgy, semiconductors, biology and medicine because of their unique capability to map trace element distributions and image buried structures without specimen preparation. ${ }^{13}$ The abilities to combine unprecedented detection sensitivity, and small detection volume allow ion beam analysis techniques to have significant advantages compared with analysis techniques associated with other microprobes (e.g., electrons and photons). ${ }^{13}$ In addition to utilizing these probes as analytical tools, recent progress has been made in the area of synthesis of high-aspect ratio nanostructures in materials. ${ }^{14,15}$ Our current research involves development of new generation HEFIB nanoprobes based on magnetic and electrostatic focusing lens systems. ${ }^{16,17}$ We have utilized the HEFIB nanoprobes to 
investigate the trace elemental distributions in biomedical systems and $\mathrm{Si}$ based electronic materials, as well as micro-fabrications in resists materials and Si wafers. ${ }^{18,19}$

\section{Experimental Facilities and Techniques}

The IBMAL in the Physics Department at the UNT currently operates four particle accelerators including a $3 \mathrm{MV}$ tandem (NEC 9SDH-2 Pelletron), a $3 \mathrm{MV}$ single ended (NEC 9SH Pelletron), a $200 \mathrm{kV}$ Texas Nuclear Cockcroft-Walton, and a HVEC AK 2.5 MV Van de Graaff. ${ }^{20}$ The accelerators are located in two basement laboratories and each has a number of beam transport lines used for modification and/or analysis of materials. The 9SDH-2 tandem and 9SH accelerators and associated beamlines, located in the main laboratory, are schematically shown in Fig. 1.

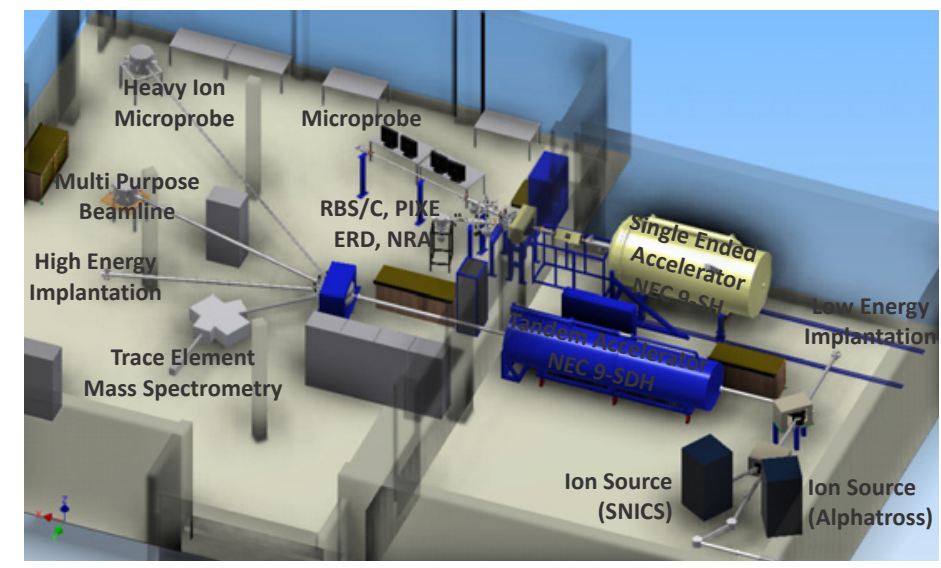

Fig. 1. The IBMAL main laboratory showing the $3 \mathrm{MV}$ tandem and the $3 \mathrm{MV}$ singled ended NEC accelerators and the associated beamlines and experimental end stations.

The NEC 3 MV 9SDH-2 tandem accelerator is equipped with three negative ion sources: two Cs-Sputter types for solid targets and a RF-type for noble gases. The negative ions, from the NEC Source of Negative Ions by Cesium sputtering (SNICS-II) ion source, are produced and accelerated to between $15-80 \mathrm{keV} .^{21,22}$ The negative ions are transported in a low-energy beam transport line to an ion implantation chamber, allowing ions or clusters to be implanted. Ion beams of $\mathrm{C}, \mathrm{Si}, \mathrm{Ge}, \mathrm{Cu}, \mathrm{Ag}, \mathrm{Zn}$, and $\mathrm{O}$ were uniformly implanted either in $\mathrm{Si}, \mathrm{SiC}$ or thermally grown $\mathrm{SiO}_{2}$ layers at energies of 15$80 \mathrm{keV}$ and for different fluences from $10^{13}$ to $10^{17}$ atom- $\mathrm{cm}^{-2}$ to produce the desired properties. $^{9-12,23}$ Alternatively, the negative ions are magnetically pre-analyzed and injected into the tandem accelerator and accelerated to higher energies as shown in Fig. 1. After acceleration, the ions are transported to the analyzing magnet, which has a massenergy product of 500 at 15 degrees. For the tandem, there are presently four high-energy beam transport lines: (1) Trace Element Accelerator Mass Spectrometry (TEAMS) for trace impurity determination of stable elements at parts-per-billion for many 
elements, ${ }^{24,25}$ (2) high-energy ion implantation equipped with electrostatic raster scanning for uniform implantation over a diameter of $\sim 5 \mathrm{~cm},{ }^{26}$ (3) multipurpose beam transport line and scattering chamber for broad-ion beam ion analysis techniques of RBS, PIXE, ERDA, NRA, single-event upset (SEU) in integrated circuits, and ion beam induced charge (IBIC) collection, and (4) heavy-ion microprobe utilizing two separated quadrupole doublet focusing lens systems from the Micro-Analytical Research Center (MARC) at the University of Melbourne. ${ }^{27}$

The 9SH single-ended accelerator, recently installed in IBMAL, is used primarily to produce sub-micron light-ion beams for elemental mapping and profiling using various ion beam analysis technique and for ion microlithography. After installation, the NEC 9SH Pelletron was upgraded by installing a new capacitive liner and terminal potential stabilization (TPS) system to reduce terminal voltage ripple as well as a new LINUXbased computer control system. The reduced terminal voltage ripple helps to lower the chromatic aberrations of the $\mathrm{MeV}$ energy ion beams and therefore reduce the probing ion beam spot size on target. The 9SH Pelletron currently has two beamlines: one for RBS/Channeling and one under construction for magnetic or electrostatic microprobe analysis. The magnetic microprobe system will utilize quadrupole lenses developed at the Louisiana Accelerator Center (LAC). ${ }^{16}$ The focusing system is currently configured to two separated doublets forming a separated quadruplet lens system. At a working distance of about $18 \mathrm{~cm}$, the focusing system is designed to have a demagnification of about 125 in both the $\mathrm{X}$ and $\mathrm{Y}$ directions. The electrostatic focusing system for $\mathrm{MeV}$ ions is currently under development and is expected to produce sub-500 $\mathrm{nm}$ spot sizes for all ions up to $3 \mathrm{MeV} / \mathrm{e}^{17}$

The $200 \mathrm{kV}$ Texas Nuclear Cockcroft-Walton accelerator uses an RF ion source for sputtering studies of different materials. The system allows measurements of the energies and angles of selected elements and molecules sputtered from a target surface. A QuantaRay Pulsed Nd-YAG laser (10 Hz, $10 \mathrm{~ns}$ pulses, up to $1 \mathrm{~J}$ per pulse at $1064 \mathrm{~nm}$ ) and associated harmonic generation apparatus is input to the target chamber for SputterInitiated Resonance Ionization spectroscopy (SIRIS) measurements. ${ }^{28}$ The laser system includes two dye lasers, ultra-high vacuum systems, and associated electronics.

The HVEC Model AK 2.5 MV Van de Graaff accelerator, which is equipped with an $\mathrm{RF}$ ion source and a multi-purpose beamline, is currently being refurbished for educational training of the students at UNT as well as for visiting students and their professors from other universities.

\section{Results and Discussion}

\subsection{Synthesis and characterization of materials for optical and electronic applications using broad ion beams}

In this section, we discuss some of our studies involving low energy ion irradiation and post-thermal annealing for the synthesis of materials for optical and electronic applications. Figure 2 shows the TEM (transmission electron microscopy) images of the 
formation of carbon nanoclusters in a $500 \mathrm{~nm}$ thick thermally grown $\mathrm{SiO}_{2}$ layer on $\mathrm{Si}$ after irradiation of $70 \mathrm{keV} \mathrm{C}$ ions at a fluence of $5 \times 10^{17}$ atoms- $\mathrm{cm}^{-2}$ and post-thermal annealing at $1100{ }^{\circ} \mathrm{C}$ for different time intervals. Figures 2(a) through 2(c) demonstrate the evolution of the carbon clusters with the increasing duration of the annealing time. ${ }^{11,29}$ Both Fig. 2(b) and 2(c) show the evolution of well-ordered carbon clusters with increasing annealing time. Further analysis of the TEM images indicates the average size of the amorphous carbon clusters is $\sim 3 \mathrm{~nm}$ for the sample annealed at $1100{ }^{\circ} \mathrm{C}$ for 90 min. Photoluminescence (PL) measurements on these samples with different time intervals are shown in Fig. 3.

Room temperature PL spectroscopy (Fig. 3(a)) indicates visible emissions from the samples pointing to the carbon ion induced defect clusters as the origin of a broad 2.0-2.4 $\mathrm{eV}$ band, and the intrinsic defects in $\mathrm{SiO}_{2}$ as the possible origin of the $\sim 2.9 \mathrm{eV}$ bands. In
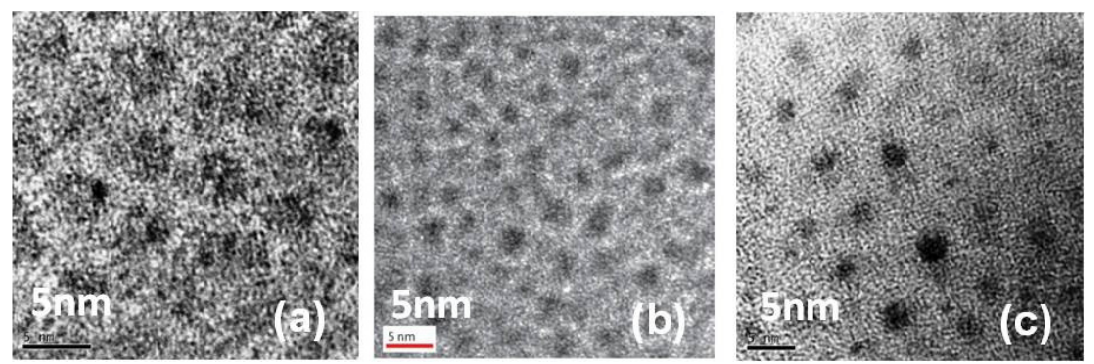

Fig. 2. High resolution TEM image taken at a depth of $200 \mathrm{~nm}$ (the peak region of the $70 \mathrm{keV}$ irradiated carbon depth profile inside $\mathrm{SiO}_{2}$ ) from the (a) as-implanted sample, and implanted samples annealed at $1100{ }^{\circ} \mathrm{C}$ for (b) 10 minutes, and (c) 90 minutes. Reprinted with permission from Ref. 29: P. R. Poudel, P. P. Poudel, J. A. Paramo, D. R. Diercks, Y. M. Strzhemechny, B. Rout and F. D. McDaniel, Journal of Nanoscience and Nanotechnology 12, 1835 (2012). Copyright@ American Scientific Publishers.

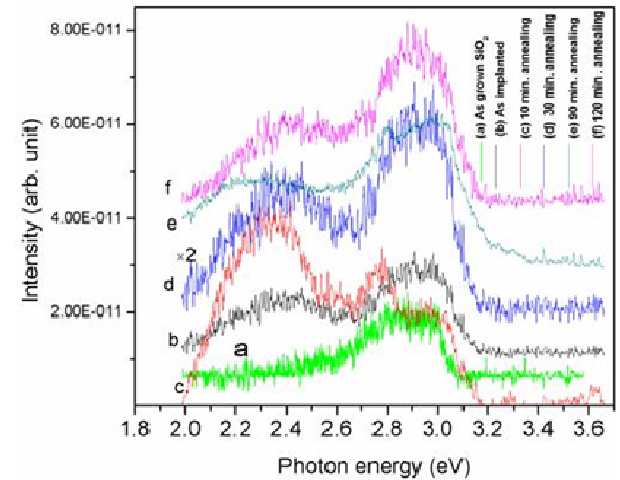

(a)

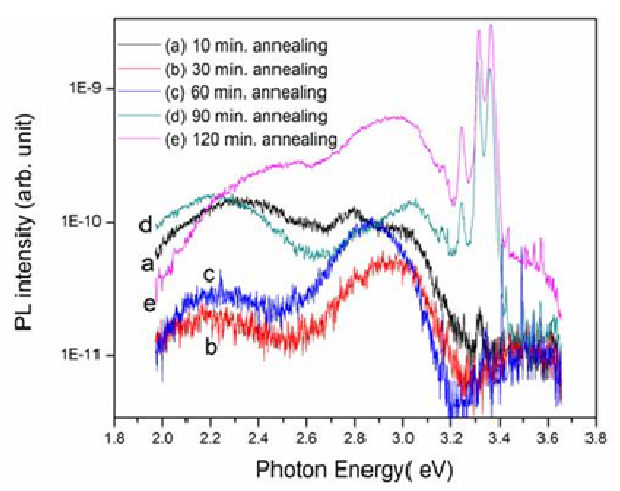

(b)

Fig. 3. (a) Room temperature PL signal from $70 \mathrm{keV}$ carbon implanted in $\mathrm{SiO}_{2}$ (fluence of $5 \times 10^{17}$ atoms- $\mathrm{cm}^{-2}$ ) annealed at $1100{ }^{\circ} \mathrm{C}$ for different time intervals. (b) The PL spectra measured at $10^{\circ} \mathrm{K}$ temperatures for the same samples. Reprinted with permission from Ref. 29: P. R. Poudel, P. P. Poudel, J. A. Paramo, D. R. Diercks, Y. M. Strzhemechny, B. Rout and F. D. McDaniel, Journal of Nanoscience and Nanotechnology 12, 1835 (2012). Copyright $@$ American Scientific Publishers. 
the low temperature PL spectra (Fig. 3(b)), two sharp and intense PL lines at $\sim 3.31 \mathrm{eV}$ and $\sim 3.34 \mathrm{eV}$ appear for the samples annealed for $10 \mathrm{~min}, 30 \mathrm{~min}, 60 \mathrm{~min}$ and $120 \mathrm{~min}$. The $\mathrm{Si}$ rich nanocrystals formed at the $\mathrm{SiO}_{2}-\mathrm{Si}$ interface are attributed as the origin of these two intense peaks seen in the annealed samples. ${ }^{11,29}$

Figure 4(a) shows the TEM image of nanoclusters synthesized by multiple lowenergy $(58,68$ and $78 \mathrm{keV}) \mathrm{Ag}$ ion irradiations in Si wafer and post-thermal annealing in a gas mixture of $4 \% \mathrm{H}_{2}+96 \% \mathrm{Ar}$ gas at $500{ }^{\circ} \mathrm{C}$ below the $\mathrm{Ag}-\mathrm{Si}$ eutectic temperature of $841{ }^{\circ} \mathrm{C}$. The size distribution of the nanoclusters are shown in Fig. 4(b) after detailed analysis of the TEM images from several regions of the implanted and annealed sample using the ImageJ package. ${ }^{30}$
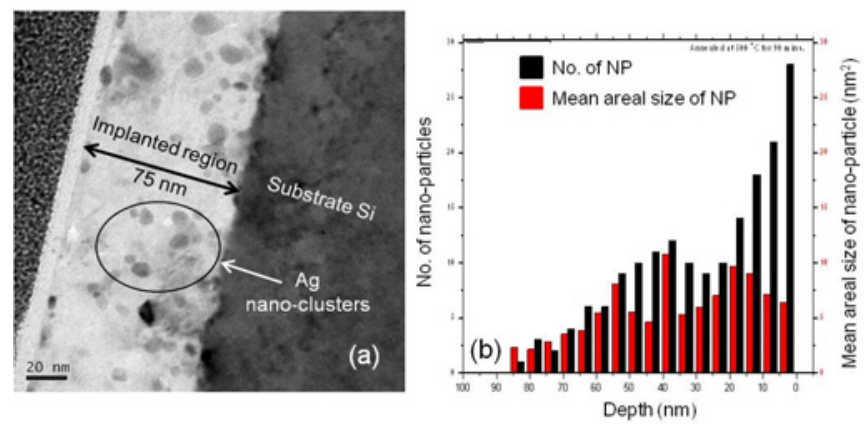

Fig. 4. (a) Cross-sectional TEM images of Ag nanocrystals synthesized due to multiple energy (78, 68, $58 \mathrm{keV}$ ) $\mathrm{Ag}$ ions implanted into $\mathrm{Si}$ and subsequently annealed at $500{ }^{\circ} \mathrm{C}$ for 90 minutes. (b) The size analysis of the $\mathrm{Ag}$ nanoclusters using the ImageJ package. ${ }^{30}$

A controlled production of the size and location of the metal nanostructures in Si will tremendously impact the development of process technology for optical and electronic applications with Si.

\subsection{Analysis of electronic materials using ion microbeams with NRA technique}

Though it is possible to quantify trace amounts of low $Z(<11)$ materials utilizing NRA techniques, the mapping of the trace amounts of low $\mathrm{Z}$ materials non-uniformly distributed in the sample still poses a great challenge. In Fig. 5, we demonstrate the

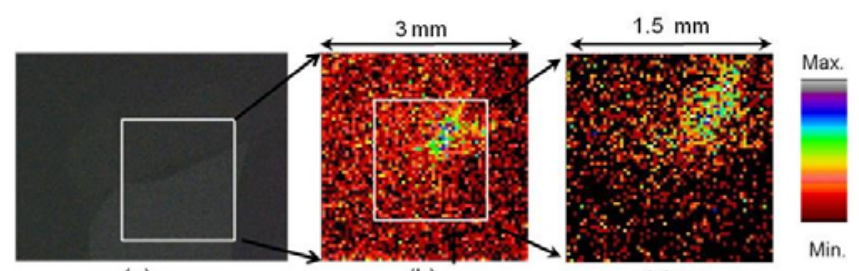

(a)

(b)

(c)

Fig. 5. Deuterium mapping of a poly-crystalline Si sample containing grain boundaries. (a) Optical image, (b) deuterium map of the white square regions in (a), and (c) map from the zoomed region of figure (b). 
capabilities to characterize trace amounts of deuterium distribution at the grain boundary of a poly-crystalline Si sample. The deuterated poly-crystalline $\mathrm{Si}$ samples ${ }^{31}$ were provided for characterization by Amethyst Research Inc. (ARI) through an industrial collaboration. The ${ }^{3} \mathrm{He}(\mathrm{d}, \mathrm{p})^{4} \mathrm{He}(\mathrm{Q}=18.352 \mathrm{MeV})$ nuclear reaction ${ }^{32}$ was used in detecting the deuterium in the sample.

The deuterium distribution mapping was performed utilizing a ${ }^{3} \mathrm{He}$ ion beam $(\sim 15 \mu \mathrm{m}$ diameter) at $700 \mathrm{keV}$ energy. A $25 \mu \mathrm{m}$ thick Mylar foil was used on top of the detector to block the backscattering signal from the incident ${ }^{3} \mathrm{He}$ as well as the ${ }^{4} \mathrm{He}$ ion beam from the NRA. Only the high energy proton beams generated due to the nuclear reaction were detected. A $300 \mathrm{~mm}^{2}$ surface barrier detector was positioned at 135 degree scattering angle (120 msr solid angle) to detect the ions due to the nuclear reaction.

\section{Conclusions}

The basic performance features and important characteristics of the various accelerator facilities at the IBMAL are summarized in Table 1, along with categories of applications.

Table 1. A summary of the important characteristics of the accelerator facilities of the IBMAL at UNT.

\begin{tabular}{|c|c|}
\hline Accelerator & Equipment Characteristics and Applications \\
\hline $\begin{array}{l}\text { NEC 9SDH-2 } \\
3 \text { MV tandem } \\
\text { Pelletron }\end{array}$ & 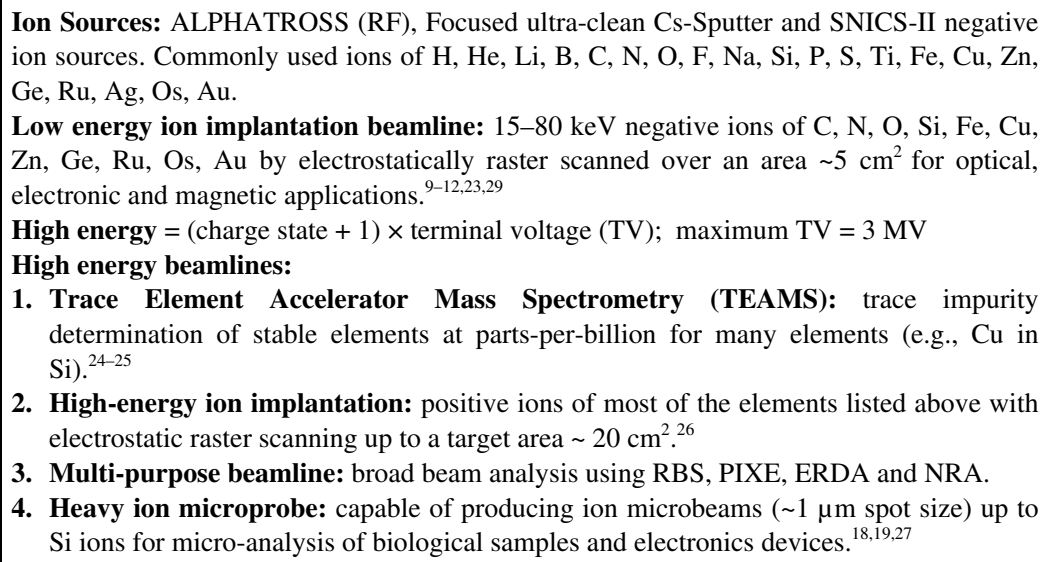 \\
\hline $\begin{array}{l}\text { NEC 9SH } \\
\text { single-ended } \\
3 \text { MV Pelletron }\end{array}$ & $\begin{array}{l}\text { Ion Source: RF ion source to produce positive ions of gaseous elements }(\mathrm{H}, \mathrm{He}, \mathrm{N}, \mathrm{Ar}) \text {. } \\
\text { Energy = (charge state) } \times \mathrm{TV} \text {; maximum } \mathrm{TV}=3 \mathrm{MV} \text {. } \\
\text { 1. Multi-purpose beamline: broad beam analysis using RBS/ ion channeling, PIXE. } \\
\text { 2. Ion microprobe: (under construction) using magnetic or electrostatic quadruplets. } \\
\text { Expected usable beam spot sizes }<500 \mathrm{~nm} \text { of } \mathrm{H} \text { or He for ion beam analysis. }{ }^{16-17}\end{array}$ \\
\hline $\begin{array}{l}\text { Texas Nuclear } \\
200 \mathrm{kV} \\
\text { Cockcroft- } \\
\text { Walton }\end{array}$ & $\begin{array}{l}\text { Ion Source: RF ion source to produce positive ions of gaseous elements }(\mathrm{H}, \mathrm{He}, \mathrm{Ne}, \mathrm{Ar}) \\
\text { Maximum TV }=200 \mathrm{kV} \text {; commonly used energy: } 50 \mathrm{kV} \text {. } \\
\text { One beamline used for measurements of the energies and angles of selected elements and } \\
\text { molecules sputtered from a target surface. }\end{array}$ \\
\hline
\end{tabular}


Some of the studies utilizing the broad beam ion irradiation from $\mathrm{keV}$ to $\mathrm{MeV}$ energies involve synthesis of materials for energy, electronic, optical and magnetic applications. With recent upgrades to the 9SH 3MV accelerator, future research will be more targeted towards development of high-throughput, quantitative, high-energy ion beam microscopy. Some of the applications of the ion beam microprobe will be in the biomedical fields involving trace element microscopy on cancer samples and pathologically degenerated rat brains.

\section{Acknowledgments}

We thank IBMAL faculty members, Professors Tilo Reinert, Duncan L. Weathers, Jerome L. Duggan, and other graduate students for their participation with the research projects. We thank Professor Y. M. Strzhemechny at Texas Christian University for the PL characterization of the samples shown in Figs. 3 and 4. We acknowledge the collaboration with Drs. O. W. Holland and K. Hossain from Amethyst Research Corporation at Ardmore, OK, USA regarding the deuterium profiling in poly-crystalline $\mathrm{Si}$ samples. We acknowledge the support from various agencies such as ONR, NSF (grant nos. 9005869, 8812331, 0083094, 9724571, and 0960222), Robert A. Welch Foundation and the UNT for the operation and research at the IBMAL.

\section{References}

1. L. T. Canham, Appl. Phys. Lett. 57, 1046 (1990).

2. Z. T. Kang, B. Arnold, C. J. Summers and B. K. Wagner, Nanotechnology 17, 4477 (2006).

3. S. Godefroo, M. Hayne, M. Jivanescu, A. Stesmans, M. Zacharias, O. I. Lebedev, G. V. Tendeloo and V. V. Moshchalkov, Nature Nanotechnology 3, 174 (2008).

4. Y. Kanemitsu, H. Uto, Y. Masumoto and Y. Maeda, Appl. Phys. Lett. 61, 2187 (1992).

5. L. J. Mitchell, F. Naab, O. W. Holland, J. L. Duggan and F. D. McDaniel, J. Non-Crystalline Solids 352, 2562 (2006).

6. D. Chen, Z. M. Liao, L. Wang, H. Z. Wang, F. Zhao, W. Y. Cheung and S. P. Wong, Opt. Mater. 23, 65 (2003).

7. S. Pillai, K. R. Catchpole, T. Trupke, G. Zhang, J. Zhao, and M. A. Green, Appl. Phys. Lett. 88, 161102 (2006).

8. G. Sahu, H. P. Lenka, D. P. Mahapatra, B. Rout and F. D. McDaniel, J. Phys.: Condensed Matter 22, 072203 (2010).

9. Lee Mitchell, Investigation of Selected Optically-Active Nanosystems Fashioned Using Ion Implantation, Ph.D. Thesis, University of North Texas (2006).

10. Khalid Hossain, A Novel Process For GeSi Thin Film Synthesis, Ph.D. Thesis, University of North Texas (2007).

11. Prakash R. Poudel, Ion Beam Synthesis of Carbon Assisted Nanosystems in Silicon based Substrates, Ph.D. Thesis, University of North Texas (2011).

12. Bimal Pandey, Prakash R. Poudel, and Duncan L. Weathers, Japanese J. Appl. Phys. 51, 11PG03 (2012).

13. M. B. H. Breese, D. N. Jamieson and P. J. C. King, Materials Analysis using a Nuclear Microprobe (Wiley \& Sons, 1996).

14. Bibhudutta Rout, Alexander D. Dymnikov, Daniel P. Zachry, Elia V. Eschenazi, Yongqiang Q. Wang, Richard R. Greco and Gary A. Glass, Nucl. Inst. Meth. B 261, 731 (2007). 
15. J. A. van Kan, P. Malar, Armin Baysic De Vera, Chen Xiao, A. A. Bettiol and F. Watt, Nucl. Instr. Meth. Phys. Res. A 645, 113 (2011).

16. Gary A. Glass, Alexander D. Dymnikov, Louis M. Houston, Jared LeBlanc, Johnny F. Dias and Bibhudutta Rout, Rev. Sci. Instr. 79, 036102 (2008).

17. A. D. Dymnikov and G. A. Glass, AIP Conf. Proc. 1336, 248 (2011).

18. F. U. Naab, F. D. McDaniel, J. L. Duggan, B. C. Boling and D. Smith, Inter. J. of PIXE 17(3/4), 177 (2007).

19. F. D. McDaniel, B. L. Doyle, C. H. Seager, D. S. Walsh, G. Vizkelethy, D. K. Brice, C. Yang, P. Rossi, M. Nigam, M. El Bouanani, G. V. Ravi Prasad, J. C. Schwartz, L. T. Mitchell and J. L. Duggan, Nucl. Instr. Meth. B 190, 1 (2002).

20. Bibhudutta Rout, Mangal S. Dhoubhadel, Prakash R. Poudel, Venkata C. Kummari, Bimal Pandey et al., Radiation Physics, AIP Conf. Proc. 1544, 11 (2013).

21. J. B. Schroeder, C. W. Howell, and G. A. Norton, Nucl. Instr. Meth. B24/25, 763 (1987).

22. R. Middleton, A Negative Ion Cookbook, HTML Version: M. Wiplich (1989); http://ibl.albany.edu/downloads/NegativeIonCookbook.pdf, last accessed 7 Nov 2013.

23. Venkata C. Kummari, Investigation of defect induced magnetism in C implanted n-type $4 \mathrm{H}$ $\mathrm{SiC}-\mathrm{A}$ new approach for transition metal free magnetic SiC, Ph.D. Thesis, University of North Texas (2013).

24. S. Matteson, D. L. Weathers, Y. D. Kim, A. M. Arrale, F. D. McDaniel, J. L. Duggan, J. M. Anthony and M. A. Douglas, Nucl. Instr. Meth. B 64, 330 (1992).

25. S. A. Datar, L. Wu, B. N. Guo, M. Nigam, D. Necsoiu, Y. J. Zhai, D. E. Smith, C. Yang, M. El Bouanani, J. J. Lee and F. D. McDaniel, Appl. Phys. Lett. 77, 3974 (2000).

26. P. R. Poudel, L. J. Mitchell, E. B. Smith, L. C. Phinney, K. Hossain, L. R. Burns, D. L. Weathers, J. L. Duggan and F. D. McDaniel, Nucl. Instr. Meth. B 261, 627 (2007).

27. D. N. Jamieson, Nucl. Instr. Meth Phys. Res. B 130, 703 (1997).

28. A. W. Bigelow, S. L. Li, S. Matteson and D. L. Weathers, in Appl. Accel. Res. Ind., eds. J. L. Duggan and I. L. Morgan, AIP Conf. Proc. 576 (AIP Press, New York, 2001), p. 108.

29. P. R. Poudel, P. P. Poudel, J. A. Paramo, D. R. Diercks, Y. M. Strzhemechny, B. Rout and F. D. McDaniel, Journal of Nanoscience and Nanotechnology 12, 1835 (2012). Copyright $\odot$ American Scientific Publishers.

30. T. J. Collins, BioTechniques 43, 25 (2007).

31. K. Hossain, O. W. Holland, R. Hellmer, B. Vanmil, L. O. Bubulac, and T. D. Golding, Jour. Elec. Mater. 39(7), 930 (2010).

32. D. J. Cherniak and W. A. Lanford, Nuclear Reaction Analysis, in Non-Destructive Elemental Analysis, ed. Z. B. Alfass (Blackwell Publishing, New York, 2001), p 308. 